\title{
Total-diet study: dietary intakes of macro elements and trace elements in Italy
}

\author{
Ginevra Lombardi-Boccia*, Altero Aguzzi, Marsilio Cappelloni, Giuseppe Di Lullo \\ and Massimo Lucarini \\ Istituto Nazionale di Ricerca per gli Alimenti e la Nutrizione (INRAN), Rome, Italy
}

(Received 19 February 2003 - Revised 19 June 2003 - Accepted 7 August 2003)

\begin{abstract}
The present study provides the dietary intakes of macro elements $(\mathrm{Ca}, \mathrm{Mg}, \mathrm{Na}, \mathrm{K}, \mathrm{P})$ and trace elements $(\mathrm{Fe}, \mathrm{Zn}, \mathrm{Cu}, \mathrm{Se})$ from the Italian total diet. The contribution of the most representative food groups of the total diet (cereals and cereal products, vegetables, fruit, milk and dairy products, meat and meat products, fish) to the daily intakes of these nutrients was also evaluated. The Italian total diet was formulated following the 'market-basket' approach. Cereals represented the primary sources of $\mathrm{Cu}(35 \%), \mathrm{Fe}(30 \%)$ and $\mathrm{Mg}(27 \%)$. About $89 \%$ of the total daily intake of $\mathrm{Fe}$ was derived from plant foods. The vegetables food group was the main source of dietary $\mathrm{K}(27 \%)$. Most of the Ca $(59 \%)$ and $\mathrm{P}(27 \%)$ was derived from the milk-and-dairy food group. Of the dietary $\mathrm{Zn}, 41 \%$ was provided by meat, which, together with the fish food group, was the primary source of Se $(20 \%)$. The adequacy of the Italian total diet with respect to nutritional elements was assessed by comparing the daily intakes with the average requirement values of the Italian recommended dietary allowances. The present findings indicated that the dietary patterns of the Italian total diet were generally consistent with current Italian dietary recommendations for both macro and trace elements. The major concern was for $\mathrm{Ca}$, for which daily intake was $76 \%$ of the average recommendation for the Italian population. It should not be ruled out that there could be a potential risk of inadequate Fe intake in some segments of the population.
\end{abstract}

Macro elements: Trace elements: Italian total diet: Food groups

The significance of macro elements and trace elements for human health is well documented (World Health Organization, 1996). In developed countries, despite the large food supply, special attention to the intake levels of some of these nutrients is required. In fact in the more affluent societies, the development of chronic diseases such as anaemia and osteoporosis, due to inadequate dietary intakes of $\mathrm{Fe}$ and $\mathrm{Ca}$ in particular segments of a population, is still observable (De Maeyer \& Adials-Tegman, 1985; Kanis et al. 1999). At the same time attention should be paid to the daily intakes of other elements such as Na because of the health risks related to a high consumption (Kaplan, 2000). Therefore to know and to up date data on the food-consumption patterns of a population and to evaluate the intake levels of both macro elements and trace elements in the total diet is of relevance for assessing the adequacy of the diet with respect to these nutritional elements and for evaluating a possible risk.

In Italy in the years 1994-6 the National Institute for Food and Nutrition Research planned a nationwide dietary survey on individuals named the INN-CA study (Turrini et al. 2001). Subsequently the food consumption data provided by the INN-CA study (Turrini et al. 2001) were utilised for formulating the list of foods making up the Italian total diet (Turrini \& Lombardi-Boccia, 2002), following the 'market-basket' criteria. The market-basket approach is in fact considered an important tool for monitoring dietary intakes of nutrients and for estimating the compliance with nutritional requirements (Pennington, 1983; Van Dokkum et al. 1989).

On these bases the present study was addressed to assess the average daily intakes of macro elements $(\mathrm{Ca}, \mathrm{Mg}, \mathrm{Na}$, $\mathrm{K}, \mathrm{P})$ and trace elements $(\mathrm{Fe}, \mathrm{Zn}, \mathrm{Cu}, \mathrm{Se})$ from the Italian total diet. In order to get a better knowledge of the main sources of these nutrients in the diet, the most representative food groups of the total diet (cereals and cereal products, vegetables, fruit, milk and dairy products, meat and meat products, fish) were also prepared. The contribution of each food group to the daily intakes of both macro and trace elements in the Italian total diet was determined. The adequacy of the Italian total diet with respect to macro elements and trace elements was assessed by comparing the estimated intakes of these nutritional elements with the average requirement values of the Italian RDA (Società Italiana di Nutrizione Umana, 1996) comprehensive of all the population group involved in the individual survey.

\section{Materials and methods}

The food-consumption data utilised for the formulation of the market basket of the Italian total diet were provided by

\footnotetext{
Abbreviation: RDA, recommended dietary allowances.

* Corresponding author: Dr G. Lombardi-Boccia, fax + 3390651494 550, email lombardiboccia@inran.it
} 
the nationwide dietary survey on individuals carried out by the National Institute for Food and Nutrition Research (Turrini et al. 2001). Particularly, the means of individual daily intakes (g) were assessed over 1968 individuals (subjects $<1$ year old were excluded). The selection process of the market basket started from 1637 foods; these were aggregated in 123 'food types' (for aggregation criteria, see Turrini \& Lombardi-Boccia, 2002). Each of the 123 food types was represented in the market basket by one or more 'prototypical foods' chosen on the basis of their consumption frequency (for example, the food type 'soft cheese' was represented in the market basket by items such as crescenza and stracchino; 'cream cheese' by gorgonzola, etc). In such a way the market basket was composed of 191 items. The selected foods were structured into twelve main food groups $(1$, milk and dairy products; 2 , cereals and cereal products; 3 , vegetables, pulses, herbs and spices; 4, meat; 5, fish and seafood; 6, eggs; 7, oils and fats; 8 , sweet products; 9 , beverages; 10 , fruit; 11 , nuts; 12 , other foods).

Other than the sample of the 'total diet', six homogeneous food groups (cereals and cereal products, vegetables, fruit, milk and dairy products, meat and meat products, fish), composed of a set of foods selected according to their consumption frequency, were also prepared and analysed. The cereals food group was composed of twenty-six prototypical foods, the vegetables food group by forty-two prototypical foods, the fruit food group by twenty prototypical foods, the milk-and-dairyproducts food group by twenty-six prototypical foods, the meat-and-meat-products food group by thirteen prototypical foods and the fish food group by fifteen prototypical foods. The food-consumption data were corrected for waste. In the preparation of the food groups some cerealbased foods (bakery products, cakes), which in the previous study (Turrini \& Lombardi-Boccia, 2002) belonged to the sugar-and-sweets group, in the present study were included in cereals and cereals products. A more detailed description of the six food groups analysed and of the processes utilised for selecting the list of foods they were composed of was reported by Turrini \& Lombardi-Boccia (2002).

The average daily intakes of both macro elements and trace elements in both the total diet and food groups were calculated $(\mathrm{mg} / \mathrm{d} ; \mu \mathrm{g} / \mathrm{d})$. The contribution of each food group to the daily intakes of macro elements and trace elements in the Italian total diet was evaluated. The adequacy of the dietary intakes was evaluated by comparing the estimated daily intakes of macro and trace elements with the average requirement values of the Italian recommended dietary allowances (RDA) (Società Italiana di Nutrizione Umana, 1996), inclusive of all the population group involved in the survey.

\section{Food preparation}

The Italian total diet was formulated in the laboratory following the market-basket approach. In order to minimise seasonal differences on mineral intake, the total diet was prepared in duplicate; in spring 2001 and in autumn 2002. Therefore the data presented in the present study were the mean values of two samples of the same total diet prepared in two different seasons. Food items were purchased in local markets and then prepared following the recipes indicated by the nationwide dietary survey of individuals (the INN-CA study; Turrini et al. 2001). Deionised water and stainless-steel utensils were used for food preparation and cooking. Precautions were taken in order to avoid oxidative or fermentative phenomena. After preparation, the foods were combined into the total-diet sample.

Samples of both the total diet and food groups were homogenised in a food blender (equipped with a stainless-steel blade) to ensure the homogeneity and stored at $-20^{\circ} \mathrm{C}$ for subsequent analysis. The samples were chemically analysed for macro elements $(\mathrm{Ca}, \mathrm{Mg}, \mathrm{Na}, \mathrm{K}, \mathrm{P})$ and trace elements $(\mathrm{Fe}, \mathrm{Zn}, \mathrm{Cu}, \mathrm{Se})$ content.

\section{Analytical procedures}

Portions of the samples $(0 \cdot 3 \mathrm{~g})$ were liquid-ashed $(4 \mathrm{ml}$ $\mathrm{HNO}_{3}+1 \mathrm{ml} \mathrm{H}_{2} \mathrm{O}_{2}$ ) in a microwave digestion system and then diluted to $25 \mathrm{ml}$ with deionised water before analyses. Analyses were performed by inductively coupled plasma-OES on a Perkin-Elmer Optima 3200XL (Norwalk, CT 06859, USA). Se analysis was performed by the inductively coupled plasma-mass spectrometer 7500a (Agilent, Palo Alto, CA, USA) equipped with autosampler ASX500 (Cetac Technologies, Omaha, NE, USA).

All reagents were of analytical grade and deionised water was used throughout. Glassware was washed in concentrated $\mathrm{HCl}$ and rinsed with deionised water. All the analyses were performed in triplicate.

\section{Standard reference materials}

Mixed diet (NBS 8431; National Bureau of Standards, Gaithersburg, MD 20899, USA), milk powder (BCR 63; Community Bureau of Reference, Brussels, Belgium), bovine muscle (BCR 184; Community Bureau of Reference, Brussels, Belgium), wholemeal flour (BCR 189; Community Bureau of Reference, Brussels, Belgium), dogfish muscle (DORM-1; National Research Council of Canada, Ottawa, Ontario, Canada) and dogfish liver (DOLT-2; National Research Council of Canada) were analysed as a check on the accuracy of the analysis.

\section{Results}

Fig. 1 shows the composition, by food groups, of the Italian total diet and the daily intakes $(\mathrm{g} / \mathrm{d})$ of each food group (non-alcoholic-beverages food group was not reported) (Turrini \& Lombardi-Boccia, 2002). As can be seen clearly in Fig. 1, the Italian total diet is a plant-centred diet, with vegetables, cereals and fruit food groups having the highest daily consumption. The six food groups analysed in the present study are shown in Fig. 1. The Italian total diet provides $8493 \mathrm{~kJ}(2030 \mathrm{kcal}) / \mathrm{d}$.

Table 1 shows the daily intakes of $\mathrm{Ca}, \mathrm{Mg}, \mathrm{Na}, \mathrm{K}$ and $\mathrm{P}$ in the Italian total diet and, in sequence, in the six food groups analysed. The amounts of macro elements in Table 1 are given in $\mathrm{mg} /$ person per $\mathrm{d}$ and in percentage of total nutrient intake. 


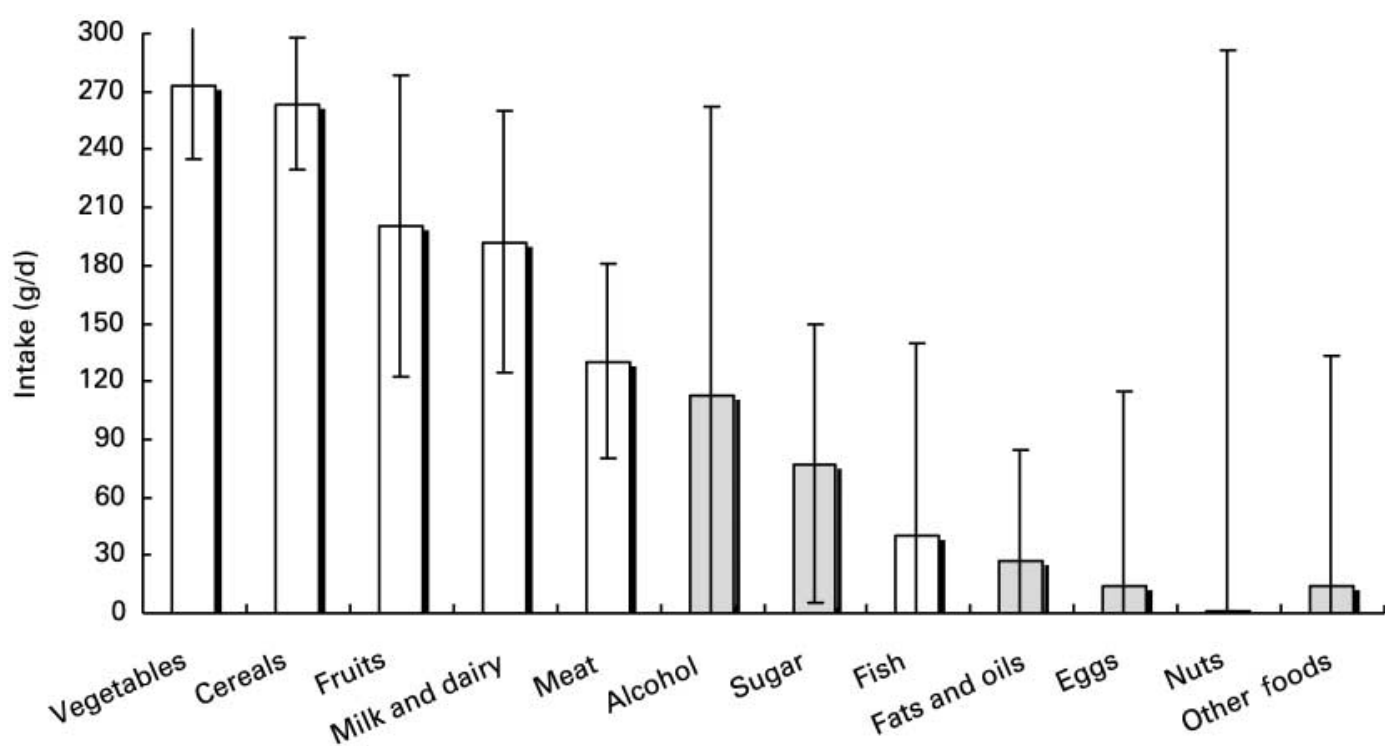

Fig. 1. Average daily intakes of foods by food group in the Italian total diet. ( $\square$ ), Food groups included in the present study; ( $\square$ ), food groups not included in the present study. The values are means, with standard deviations represented by vertical bars. (From Turrini \& LombardiBoccia, 2002.)

Ca daily intake in the Italian total diet is of $738 \mathrm{mg} /$ person perd. The milk-and-dairy food group makes the greatest contribution to dietary Ca intake; about $59 \%$ of the total daily intake of $\mathrm{Ca}$ derives from this food group. The vegetables and cereals food groups contribute about 11 and $10 \%$ respectively, to the total daily intake of $\mathrm{Ca}$. The remaining food groups provide extremely low amounts proportionally of this macro element. Although drinking water is not included in the analysed food groups, its contribution to the daily intake of $\mathrm{Ca}$ is consistent; about $10 \%$ of the total daily $\mathrm{Ca}$ intake (personal data).

$\mathrm{Mg}$ is widely distributed in foods; consequently, most of the food groups analysed provide good amounts of this macro element. The highest $\mathrm{Mg}$ daily intake, $71 \mathrm{mg} /$ person perd, is supplied by cereals which represents $27 \%$ of the total daily intake of $\mathrm{Mg}$. Vegetables are another important source of $\mathrm{Mg}(19 \%)$.

$\mathrm{Na}$ intake is of $3.8 \mathrm{~g} /$ person per $\mathrm{d}$ (Table 1); this includes the salt added during cooking and at the table. The discretionary salt, assessed by the dietary recall (Turrini et al.
2001) and added to the total diet, is $7 \cdot 3 \mathrm{~g}$ which corresponds to $2.9 \mathrm{~g} \mathrm{Na}$ (part of the discretionary salt was lost during food preparations; for example, drying pasta, etc). The six food groups analysed were prepared without the addition of discretionary salt. The main sources of $\mathrm{Na}$ in the Italian total diet are the cereals and meat-and-meat-products food groups, which contribute 18 and $13 \%$, respectively, to the total $\mathrm{Na}$ intake. The milk-and-dairy and fish food groups provide about 7 and $6 \%$, respectively, of the total daily $\mathrm{Na}$ intake.

As far as $\mathrm{K}$ is concerned, $2.91 \mathrm{~g} /$ person per $\mathrm{d}$ is supplied daily by the total diet (Table 1 ). Most of the $\mathrm{K}$ derives from vegetables $(26 \%)$ followed by meat and meat products $(19 \%)$. Both the fruits and cereals food groups contribute $10 \%$ of the total daily $\mathrm{K}$ intake.

The daily intake of $\mathrm{P}$ is about $1.44 \mathrm{~g} /$ person per $\mathrm{d}$ (Table 1). Major contributors to the daily $\mathrm{P}$ intake are protein-rich foods. Therefore most $\mathrm{P}$ comes from the milk-and-dairy food group (27\%) followed by the meatand-meat-products food group (23\%). Cereals contribute $22 \%$ to the total daily intake of P.

Table 1. Daily intakes of calcium, magnesium, sodium, potassium and phosphorus in the Italian total diet: contributions of some food groups to daily intakes

(Mean values and standard deviations)

\begin{tabular}{|c|c|c|c|c|c|c|c|c|c|c|c|c|c|c|c|}
\hline & \multicolumn{3}{|c|}{$\mathrm{Ca}$} & \multicolumn{3}{|c|}{$\mathrm{Mg}$} & \multicolumn{3}{|c|}{$\mathrm{Na}$} & \multicolumn{3}{|c|}{ K } & \multicolumn{3}{|c|}{$P$} \\
\hline & \multicolumn{2}{|c|}{$\mathrm{mg} / \mathrm{d}$} & \multirow[b]{2}{*}{$\%$} & \multicolumn{2}{|c|}{$\mathrm{mg} / \mathrm{d}$} & \multirow[b]{2}{*}{$\%$} & \multicolumn{2}{|c|}{$\mathrm{mg} / \mathrm{d}$} & \multirow[b]{2}{*}{$\%$} & \multicolumn{2}{|c|}{$\mathrm{mg} / \mathrm{d}$} & \multirow[b]{2}{*}{$\%$} & \multicolumn{2}{|c|}{$\mathrm{mg} / \mathrm{d}$} & \multirow[b]{2}{*}{$\%$} \\
\hline & Mean & SD & & Mean & SD & & Mean & SD & & Mean & SD & & Mean & $S D$ & \\
\hline $\begin{array}{l}\text { Total diet } \\
\text { Food groups }\end{array}$ & 738 & 120 & & 262 & 21 & & 3812 & 272 & & 2913 & 210 & & 1444 & 79 & \\
\hline Cereals and cereal products & 76 & 22 & 10 & 71 & 3 & 27 & 693 & 108 & 18 & 299 & 86 & 10 & 320 & 35 & 22 \\
\hline Vegetables & 78 & 23 & 11 & 49 & 9 & 19 & 139 & 35 & 4 & 744 & 4 & 26 & 127 & 13 & 9 \\
\hline Fruits & 22 & 2 & 3 & 17 & 2 & 7 & 10 & 4 & 0.2 & 302 & 18 & 10 & 37 & 1 & 3 \\
\hline Milk and dairy products & 437 & 58 & 59 & 28 & 1 & 11 & 257 & 7 & 7 & 265 & 59 & 9 & 395 & 76 & 27 \\
\hline Meat and meat products & 14 & 7 & 2 & 35 & 6 & 13 & 500 & 140 & 13 & 547 & 45 & 19 & 326 & 56 & 23 \\
\hline Fish & 23 & 11 & 3 & 14 & 1 & 5 & 227 & 26 & 6 & 117 & 23 & 4 & 103 & 24 & 7 \\
\hline
\end{tabular}


Table 2. Daily intakes of iron, zinc, copper and selenium in the Italian total diet: contributions of some food groups to daily intakes (Mean values and standard deviations)

\begin{tabular}{|c|c|c|c|c|c|c|c|c|c|c|c|c|}
\hline & \multicolumn{3}{|c|}{$\mathrm{Fe}$} & \multicolumn{3}{|c|}{$\mathrm{Zn}$} & \multicolumn{3}{|c|}{$\mathrm{Cu}$} & \multicolumn{3}{|c|}{$\mathrm{Se}$} \\
\hline & \multicolumn{2}{|c|}{$\mathrm{mg} / \mathrm{d}$} & \multirow[b]{2}{*}{$\%$} & \multicolumn{2}{|c|}{$\mathrm{mg} / \mathrm{d}$} & \multirow[b]{2}{*}{$\%$} & \multicolumn{2}{|c|}{$\mathrm{mg} / \mathrm{d}$} & \multirow[b]{2}{*}{$\%$} & \multicolumn{2}{|c|}{$\mu \mathrm{g} / \mathrm{d}$} & \\
\hline & Mean & $\overline{S D}$ & & Mean & $\overline{S D}$ & & Mean & $\overline{S D}$ & & Mean & $\overline{S D}$ & $\%$ \\
\hline $\begin{array}{l}\text { Total diet } \\
\text { Food groups }\end{array}$ & $12 \cdot 7$ & $1 \cdot 2$ & & $10 \cdot 6$ & 0.9 & & $1 \cdot 2$ & 0.14 & & $103 \cdot 6$ & 0.02 & \\
\hline Cereals and cereal products & 3.80 & 0.08 & 30 & 1.90 & 0.06 & 18 & 0.42 & 0.05 & 35 & $16 \cdot 00$ & 0.01 & 15 \\
\hline Vegetables & $3 \cdot 20$ & 0.50 & 25 & 0.70 & 0.01 & 7 & 0.30 & 0.04 & 25 & 14.00 & 0.01 & 14 \\
\hline Fruits & 0.40 & 0.07 & 3 & 0.60 & 0.30 & 6 & 0.12 & 0.04 & 10 & 4.00 & 0.01 & \\
\hline Milk and dairy products & 0.40 & 0.08 & 3 & 1.8 & 0.02 & 17 & 0.13 & 0.05 & 11 & $10 \cdot 00$ & 0.02 & 10 \\
\hline Meat and meat products & 2.50 & 0.08 & 20 & 4.3 & 1.06 & 41 & 0.14 & 0.07 & 12 & 21.00 & 0.06 & 20 \\
\hline Fish & 0.60 & $0 \cdot 10$ & 5 & 0.4 & 0.07 & 4 & 0.03 & 0.06 & 3 & 2.001 & 0.08 & 20 \\
\hline
\end{tabular}

Table 2 shows the daily intakes of $\mathrm{Fe}, \mathrm{Zn}, \mathrm{Cu}$ and $\mathrm{Se}$ in the Italian total diet. The daily Fe intake is $12.7 \mathrm{mg}$. In the Italian total diet about $89 \%$ of the Fe is non-haem Fe. Most of this is supplied by plant foods, namely $58 \%$ of it comes from the vegetables, cereals and fruits food groups (Table 2). Haem-Fe in the total diet represents about $11 \%$ of the total Fe intake.

The daily intake of $\mathrm{Zn}$ in the Italian total diet is $10.6 \mathrm{mg} /$ person per $\mathrm{d}$ (Table 2). Meat and meat products represent the basic source of $\mathrm{Zn}$ in the diet, providing $41 \%$ of the total daily intake of this element. The cereals and milkand-dairy food groups are significant sources also, contributing 18 and $17 \%$ respectively, to the total $\mathrm{Zn}$ intake.

The total dietary $\mathrm{Cu}$ intake is $1.2 \mathrm{mg} /$ person per $\mathrm{d}$ (Table 2). Of this, $70 \%$ is derived from plant foods; the greatest amount is provided by the cereals $(35 \%)$ followed by the vegetables $(25 \%)$ food groups. The contribution of meat and meat products to the total daily intake of $\mathrm{Cu}$ is about $12 \%$.

The meat-and-meat-products and fish food groups are the main sources of Se in the Italian total diet, both supplying about $20 \%$ of the total daily intake (Table 2). The cereals and vegetables food groups also provide good amounts of this element ( 15 and $14 \%$, respectively).

In order to evaluate the adequacy of the Italian total diet with respect to the macro and trace elements that were studied, the daily intakes of the nutritional elements were compared with the Italian RDA (Società Italiana di Nutrizione Umana, 1996) (Fig. 2). Because the total-diet study is based on the chemical analysis of a diet for which the consumption data are not differentiated by age or sex, the daily intakes of macro elements and trace elements were compared with the average requirement values of the Italian RDA estimated from all the population group comprised in the survey (Turrini \& Lombardi-Boccia, 2002). The age and sex of the subjects were considered in the calculation.

As shown in Fig. 2, Ca represents $76 \%$ of the average value of the RDA for the population group. Of the macro elements reported in Fig. 2, only $\mathrm{P}$ exceeds the average value of the RDA; on the other hand $\mathrm{P}$ is present in numerous foods and supplied by a number of food additives. The $\mathrm{Ca}: \mathrm{P}$ ratio in the Italian total diet is $0 \cdot 5$. Daily $\mathrm{K}$ intake is close to the requirements (Fig. 2), being $98.5 \%$ of the average value of the RDA. Since the Italian RDA for $\mathrm{Mg}$ and

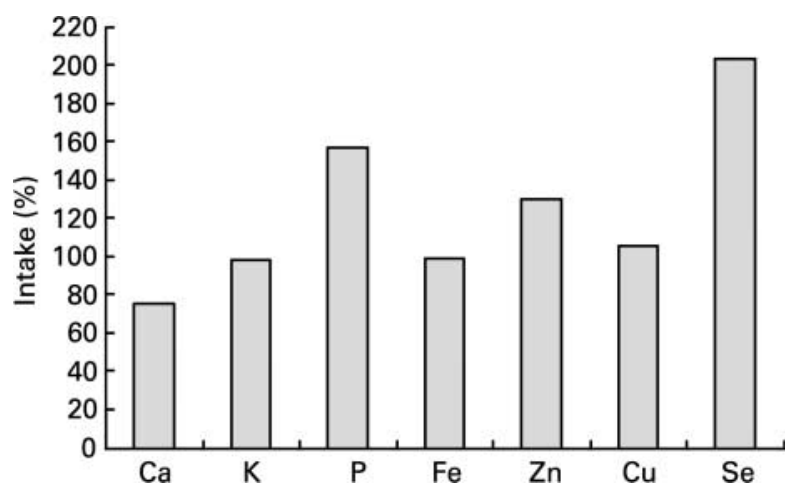

Fig. 2. Daily intakes of some macro elements $(\mathrm{Ca}, \mathrm{K}$ and $\mathrm{P})$ and trace elements ( $\mathrm{Fe}, \mathrm{Zn}, \mathrm{Cu}$ and $\mathrm{Se}$ ) expressed as a percentage of the Italian recommended dietary allowances.

$\mathrm{Na}$ are range values rather than strict values of daily intakes (Società Italiana di Nutrizione Umana, 1996), these macro elements are not reported in Fig. 2. The daily intake of $\mathrm{Mg}$ in the Italian total diet (Table 1) is in the range considered optimal by the Italian RDA (150-500 mg/person per d) (Società Italiana di Nutrizione Umana, 1996). However the levels of $\mathrm{Na}$ in the diet (Table 1) exceed the upper limit considered safe by the Italian RDA (0.575-3.5 g/person per d).

As far as the trace elements are concerned, daily intakes of $\mathrm{Fe}$ and $\mathrm{Cu}$ are close to the average requirements estimated on all the population group being 99.8 and $106 \%$, respectively (Fig. 2). Both $\mathrm{Zn}$ and Se exceed the recommendations, being well above the average values of the requirements for the population comprised in the survey (Fig. 2).

\section{Discussion}

The study of total diet is a tool for achieving an accurate knowledge of a population's diet, either as food-consumption patterns or as intake levels of nutrients, bioactive compounds and toxicants. Even though the daily intake data provided by total-diet studies are insufficient to establish the adequacy of a diet, they can offer important information about the nutritional quality of national diets and about potential nutritional problems. The intake data can be used to examine a specific element of interest. 
The present study focused on nutritional elements in the Italian total diet and provided in particular information on the average dietary intakes of both macro elements and trace elements in Italy. Furthermore the present findings allowed the identification of the specific food groups most responsible for major and minor contributions to the intakes of these nutritional elements and, consequently, to get more insight into the characteristics of the Italian total diet.

Most of the nutritional elements in the Italian total diet are derived from plant foods: the cereals food group in particular was the primary source of $\mathrm{Mg}, \mathrm{Na}, \mathrm{Fe}$ and $\mathrm{Cu}$; the vegetables food group the primary source of $\mathrm{K}$. On the other hand, the macro elements $\mathrm{Ca}$ and $\mathrm{P}$, and the trace elements $\mathrm{Zn}$ and Se, were derived mainly from foods of animal origin; the milk-and-dairy food group for $\mathrm{Ca}$ and $\mathrm{P}$ and the meat-and-meat-products food group for $\mathrm{Zn}$ and Se.

The data presented in the present study indicated that the dietary patterns of the Italian total diet, with respect to macro elements and trace elements nutriture, were generally consistent with current Italian dietary recommendations (Società Italiana di Nutrizione Umana, 1996). Because the comparison of both macro and trace elements intakes with the Italian RDA (Società Italiana di Nutrizione Umana, 1996) was made on average requirements estimated on all the population comprised in the survey, the possibility of the risk of inadequate intake for some of these elements in segments of the population must be considered. Attention in particular should be paid to $\mathrm{Ca}$ nutriture, for which the daily intake was about $76 \%$ of the average recommendation. A previous study (Scaccini et al. 1992) carried out on selected age-sex groups showed that $\mathrm{Ca}$ intake was of concern for segments of the Italian population. Fe is another element for which a potential risk of low intake should not be ruled out. The European Prospective Investigation into Cancer and Nutrition study (Slimani et al. 2002) showed a substantial geographic variation in dietary patterns and food-group intake throughout Europe, a variation that follows a south-north gradient. The study outlined in particular a similarity in dietary patterns between Italy and Greece, both characterised by high plant-food consumption compared with the other European Prospective Investigation into Cancer and Nutrition countries. Little data on total-diet study in Europe are available. Van Dokkum (1998), in a report on trace elements intake in Europe, stressed that the intake of $\mathrm{Fe}, \mathrm{Cu}$ and $\mathrm{Se}$ in particular appeared to be inadequate (when compared with the RDA) in several countries. In a study dealing with the dietary intake of macro and trace elements in Dutch population groups (Lowik et al. 1994), $\mathrm{Fe}$ was the major health concern, for which intake was less than optimal in parts of the population.
In conclusion the present findings tend to confirm the trend evidenced by studies carried out in other European countries which expressed concerns in particular for $\mathrm{Fe}$ and $\mathrm{Ca}$ nutriture. Therefore studies aimed at the evaluation of the nutritional status of these two nutrients in well-identified segments of the Italian population should be addressed.

\section{Acknowledgements}

The study was performed as part of the research 'Study on the nutritional quality of the Italian total diet: nutrient intakes, composition and stability of the lipid fraction, risk of cardiovascular diseases' supported by the National Council of Researches.

\section{References}

De Maeyer EM \& Adials-Tegman M (1985) The prevalence and causes of anemia in the world. World Health Stat $Q$ 38, 302-314.

Kanis J, Johnell O, Gullberg B, et al. (1999) Risk factors for hip fracture in men from southern Europe: the MEDOS study. Mediterranean Osteoporosis study. Osteoporosis Int 9, 45-54.

Kaplan NM (2000) The dietary guideline for sodium: should we shake it up? No. Am J Clin Nutr 71, 1020-1026.

Lowik MRH, Brussaard JH, Hulshof K, et al. (1994) Adequacy of the diet in the Netherlands in 1987-1988 (Dutch nutrition surveillance system). Int J Food Sci Nutr 45, Suppl. 1, S1-S62.

Pennington JAT (1983) Revision of the total diet study food list and diets. JADA 82, 166-173.

Scaccini C, Sette S, Mariotti S, Verdecchia A \& Ferro-Luzzi A (1992) Nutrient adequacy of dietary intakes of elderly. Age \& Nutr 3, 41-47.

Slimani N, Fahey M, Welch A, et al. (2002) Diversity of dietary patterns observed in the European Prospective Investigation into Cancer and Nutrition (EPIC) project. Public Health Nutr 5, $1311-1328$.

Società Italiana di Nutrizione Umana (1996) Livelli di Assunzione Raccomandati di Energia e Nutrienti per la Popolazione Italiana. Rome: Società Italiana di Nutrizione Umana.

Turrini A \& Lombardi-Boccia G (2002) The formulation of the market basket for evaluating the Italian total diet 1994-96. Nutr Res 22, 1151-1162.

Turrini A, Saba A, Perrone D, Cialfa E \& D'Amicis A (2001) Food consumption patterns in Italy: the INN-CA study 1994-1996. Eur J Clin Nutr 55, 571-588.

Van Dokkum W (1998) Trace element intake in Europe: safe and adequate? Bibl Nutr Dieta 54, 8-17.

Van Dokkum W, de Vos RH, Muys T \& Wesstra JA (1989) Minerals and trace elements in total diets in The Netherlands. $\mathrm{Br} J$ Nutr 61, 7-15.

World Health Organization (1996) Trace Elements in Human Health and Nutrition. Geneva, Switzerland: WHO Publications. 